\title{
Determination of Initial and Final Set of Ternary Mortars and Compressive Strength with Regard to Temperature Variation
}

\author{
Alan Richardson, Susan Dawson, Giovanni Pesce \\ Northumbria University, Newcastle upon Tyne, NE1 8SA, UK. \\ E-mail: alan.richardson@northumbria.ac.uk
}

Received: 7 September 2018; Accepted: 26 September 2018; Available online: 15 January 2019

\begin{abstract}
The research examined herein classifies initial and final set times, for samples of ternary mortars composed of CEM 1 (52.5) and Ground Granulated Blast Furnace Slag (GGBS). The samples tested comprised of different CEM 1 and GGBS proportions. The mixes used, ranged from 100\% CEM1 where this component was replaced at $10 \%$ increments by mass terminating at a $20 \%$ CEM 1 content. With a reduction in cement content, the balance of the total required binder was being made up with GGBS. The ternary mortar cubes were tested for initial and final set times at average ambient room temperature $\left(19.7-22.2{ }^{\circ} \mathrm{C}\right)$ and temperatures of 5 and 40 degrees Celsius. The findings highlighted the additional time required for initial and final set times at reduced temperatures and it also highlighted the further additional time for initial and final set times when GGBS is used as a cement replacement in progressively increasing quantities. Initial and final set times at 40 degrees Celsius were faster than ambient and 5 degrees Celsius, however the difference between initial and final set times was much reduced at 40 degrees Celsius. Both temperature and cement replacement affected the compressive strength at a curing period of 28 days, however GGBS is known to take longer than CEM1 to achieve a given strength development of say $90 \%$ of the final or ultimate strength. The two factors of temperature and cement replacement have a significant impact on setting times.
\end{abstract}

Keywords: CEM1; Ground granulated blast furnace slag (GGBS); Initial and final setting times strength; Temperature; Environment.

\section{Introduction}

The benefits of using GGBS in concrete as a cement replacement are many and range from freeze/thaw resistance [1], to the control of internal building temperatures [2,3].

Ground granulated blast furnace slag (GGBS) is mostly used combined with Portland cement for diverse purposes [4]. Concrete made with GGBS has several benefits, including improved durability, workability and economic benefits [5]. One drawback in the utilization of GGBS in cement mixes is that its strength development is considerably slower under standard $20^{\circ} \mathrm{C}$ curing conditions when compared to pure cement mixes, despite the ultimate strength being higher for the same water -binder ratio [6]. Ground granulated blast furnace slag is not therefore used in cases where high early age strength is required. Nonetheless hydration of GGBS is more sensitive to temperature than Portland cement and there are studies showing that at higher early age temperatures, the strength development of GGBS mixes with cement is significantly increased [7].

Temperature affects concrete setting behaviour due to it affecting the hydration rate of cement. A clear linear relationship between concrete initial setting time and temperature was established as shown in Figure 1. Additionally, a linear relationship between the inverse of setting time and inverse of absolute temperature was also found. Conclusions can be drawn, that the setting times for any temperature can be predicted based on the linear relationship by only measuring setting times at two extreme temperatures. Figure $1 \mathrm{~b}$ can be used to determine the activation energy. [8].

Figure 2a presents a compelling reflex of temperature on concrete setting time. The temperatures have their range for hot (from 32 to $41{ }^{\circ} \mathrm{C}$ ), control $\left(20\right.$ to $24{ }^{\circ} \mathrm{C}$ ) and cold $\left(4\right.$ to $13{ }^{\circ} \mathrm{C}$ ). The concrete strength development is considerably faster at the hot condition in comparison to the cold condition. Already checking the second image (Figure $2 \mathrm{~b}$ ) is possible to see the setting - maturity relationship by using equivalent age method considering the activation energy [10].

The effects of GGBS on concrete setting time depend on factors such as slag composition, percentage replacement and curing temperature. Usually the slag replacement at a lower temperature increases the concrete setting time, especially for slag replacement higher than $40 \%$ [11]. According to Eren [12] temperature is the fundamental factor for slag when influencing the setting time. For a temperature value greater that $20^{\circ} \mathrm{C}$, it was 
shown that $30 \%$ and $50 \%$ slag replacements decrease the setting time of concrete. However research from Alshamsi [13] suggested that for slag replacements of 30, 50 and 70\%, there is no delay on setting time at temperature above $35^{\circ} \mathrm{C}$. This aspect is worthy of further investigation.
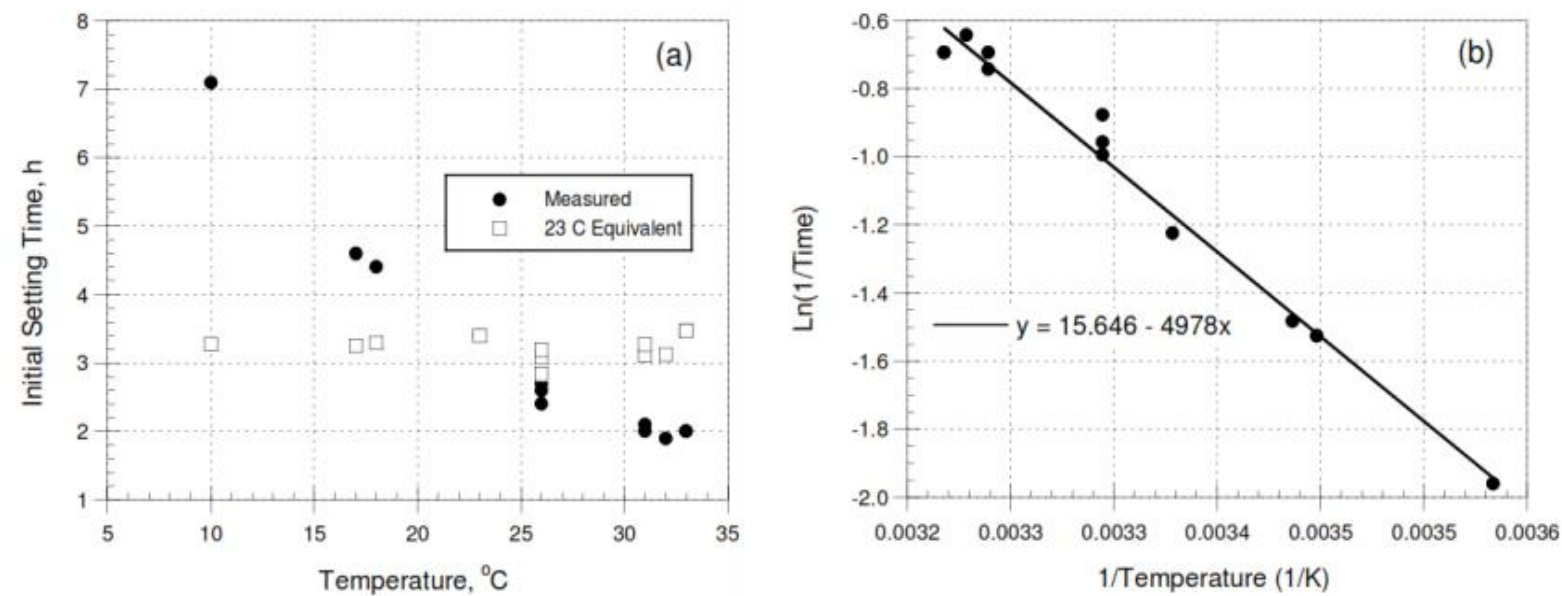

Figure 1a Initial Setting time vs. temperature (1b) inverse of setting time vs. inverse of absolute temperature [9]
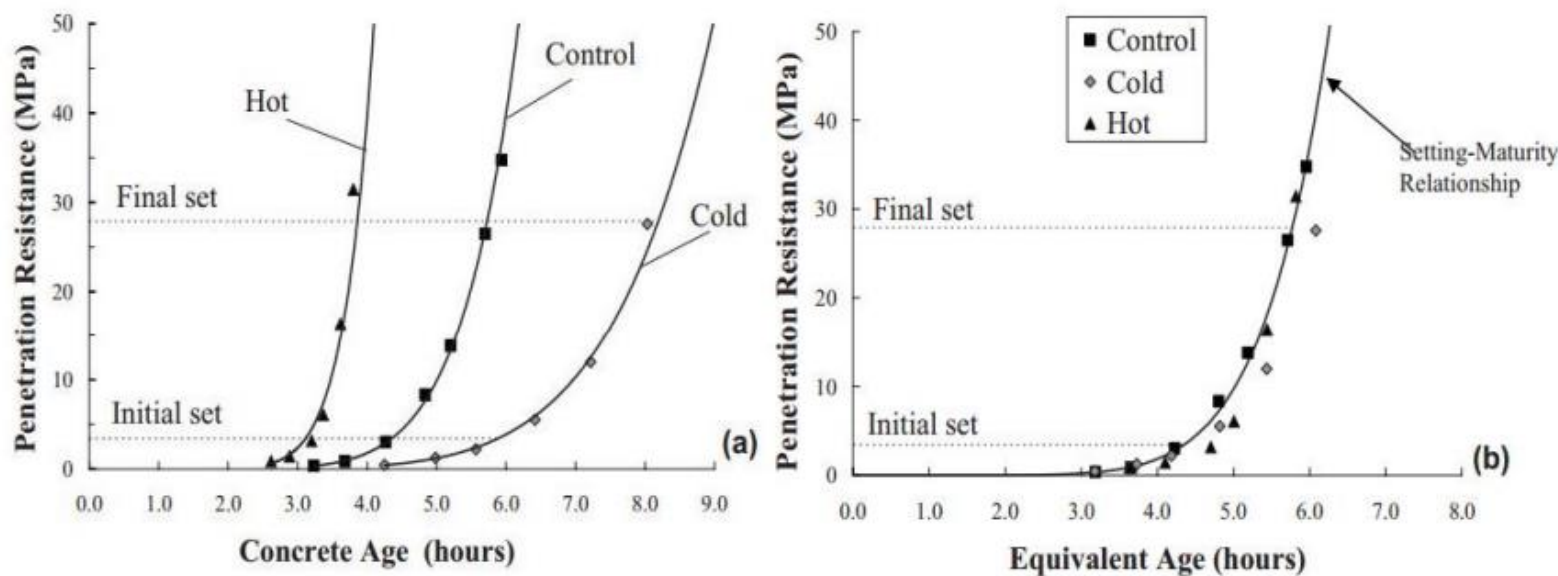

Figure 2. Results for the $30 \%$ slag mixture: (a) effect of temperature on setting time, (b) setting - maturity relationship [11].

\section{Methodology}

The dry component parts of CEM1 and GGBS were mixed into a uniform colour prior to the addition of water to make a consistently even grout at a water cement/binder ratio of 0.5 . The stopwatch was started once the mix began, adding carefully more water to ensure a consistent material.

The initial mix, took between 10 and 15 minutes to complete, including the filling of the moulds in three layers and tamping them with the rod in order to compact the mass and remove air voids. The top of the sample was levelled with the use of a plastering trowel and was considered ready to be tested.

These nine samples of a single binder content were referenced and divided into three groups. One group was stored during the setting tests in ambient temperature conditions and the other in a chamber with controlled air temperature of $40^{\circ}$ Celsius.

Following the final set results being obtained two thirds of the mortar specimens were placed into temperature controlled chambers at $5^{\circ}$ and $40^{\circ}$ Celsius respectively for 28 days curing time. The remaining one third of the samples were air cured at ambient temperatures.

BS EN 196-3:2005 Methods of testing cement - Part 3 [14]: Determination of setting times and soundness was used for the test procedure using the Vicat apparatus.

\section{Results}


The ambient temperature during the preparation and testing of the ternary mortars, was recorded and is displayed in Table 1.

Table 1. Temperature records during sample preparation and testing

\begin{tabular}{|c|c|c|c|c|c|c|c|}
\hline \multicolumn{8}{|c|}{ Day of preparation of 100} \\
\hline Time & $9 \mathrm{~h} 45$ & $10 \mathrm{~h} 45$ & $12 \mathrm{~h} 00$ & $13 \mathrm{~h} 45$ & $14 \mathrm{~h} 45$ & $15 \mathrm{~h} 30$ & Mean \\
\hline Temperature $\left({ }^{\circ} \mathrm{C}\right)$ & 20.5 & 21.0 & 22.2 & 22.0 & 23.0 & 22.8 & 21.9 \\
\hline \multicolumn{8}{|c|}{ Day of preparation of 90 and 80} \\
\hline Time & $9 h 50$ & $11 \mathrm{~h} 00$ & $12 \mathrm{~h} 00$ & $13 \mathrm{~h} 00$ & $14 \mathrm{~h} 00$ & $15 \mathrm{~h} 00$ & Mean \\
\hline Temperature $\left({ }^{\circ} \mathbf{C}\right)$ & 19.0 & 21.3 & 21.6 & 22.0 & 22.5 & 22.6 & 21.5 \\
\hline \multicolumn{8}{|c|}{ Day of preparation of 70 and 60} \\
\hline Time & $10 \mathrm{~h} 00$ & $11 \mathrm{~h} 00$ & $12 \mathrm{~h} 00$ & $13 \mathrm{~h} 00$ & $14 \mathrm{~h} 00$ & $16 \mathrm{~h} 00$ & Mean \\
\hline Temperature $\left({ }^{\circ} \mathbf{C}\right)$ & 19.5 & 20.0 & 19.5 & 19.5 & 19.6 & 20.0 & 19.7 \\
\hline \multicolumn{8}{|c|}{ Day of preparation of 50 and 40} \\
\hline Time & $10 \mathrm{~h} 00$ & $11 \mathrm{~h} 00$ & $12 \mathrm{~h} 00$ & $13 \mathrm{~h} 00$ & $15 \mathrm{~h} 00$ & $16 \mathrm{~h} 00$ & Mean \\
\hline Temperature $\left({ }^{\circ} \mathbf{C}\right)$ & 21.0 & 21.6 & 21.8 & 22.0 & 22.4 & 22.6 & 21.9 \\
\hline \multicolumn{8}{|c|}{ Day of preparation of 30 and 20} \\
\hline Time & $10 \mathrm{~h} 00$ & $11 \mathrm{~h} 00$ & $12 \mathrm{~h} 00$ & $13 \mathrm{~h} 00$ & $14 \mathrm{~h} 00$ & $15 \mathrm{~h} 30$ & Mean \\
\hline Temperature $\left({ }^{\circ} \mathbf{C}\right)$ & 19.5 & 19.8 & 19.8 & 22.2 & 22.5 & 19.4 & 20.5 \\
\hline
\end{tabular}

The initial and final setting times are displayed in Figure 3.

At ambient temperatures the results displayed in Figure 3 show a clear association with the use of GGBS and reaction and setting times. Between the cement content range of 100 and 20\%, examining the initial set time, there is a $447 \%$ increase in the time and when examining the final set there is a $180 \%$ increase in time.

The samples tested at $40^{\circ} \mathrm{C}$ displayed less of a change between initial and final set although the initial and final setting times were much shorter than the ambient sample times. The difference between the $40^{\circ} \mathrm{C}$ initial setting time at $100 \%$ OPC and an $80 \%$ replacement was $32 \%$ and the difference between the final setting time at $100 \%$ OPC and an $80 \%$ replacement was $16 \%$. This is a significant change compared to ambient air temperature testing.

The comparative compressive strength is displayed in Figure 4 that shows a reduction in compressive strength when examined between $100 \%$ cement and $20 \%$ cement with an $80 \%$ GGBS as a cement replacement. The percentage drop in strength was $32.5 \% / 20.7 \% / 53.5 \%$ respectively; $40^{\circ} \mathrm{C}$, ambient and $5^{\circ} \mathrm{C}$ curing. The effect of a higher temperature clearly shows an accelerated curing at all replacement contents, whereas the converse of this is true when the temperature is reduced.

There is virtually no difference in strength development between the cement content values of $80 \%$ to $40 \%$ at $5^{\circ} \mathrm{C}$. The ambient strength at 28 days displayed very little change until a $70 \%$ replacement was used. The $70 \%$ cement content showed a slight dip in strength which was not expected and in keeping with the surrounding results.

\section{Discussion}

The implications of using GGBS as a cement replacement has positive and negative attributes that will be determined by its role in the construction process, for instance a client may wish for a durable low maintenance concrete, GGBS will go a long way in providing this solution to the clients brief.

The contractor may need to speed up the construction process to be financially viable by reducing indirect costs associated with being on site over the duration of the contract. This may rule out using GGBS as a cement replacement if the work was on the critical path.

The environmentalist may wish to use a waste product that was once land filled. The use of GGBS will fulfil this need, saving land fill with its associated costs. There is a question mark against the supply of GGBS as steel from iron ore is less used due to major steel recycling efforts [15].

Site location will determine the rate of curing. The Middle East would see little change to the critical path using high percentages of GGBS as a cement replacement, whereas Norway might suffer extended delays using GGBS, depending upon the time of the year concrete was laid. 


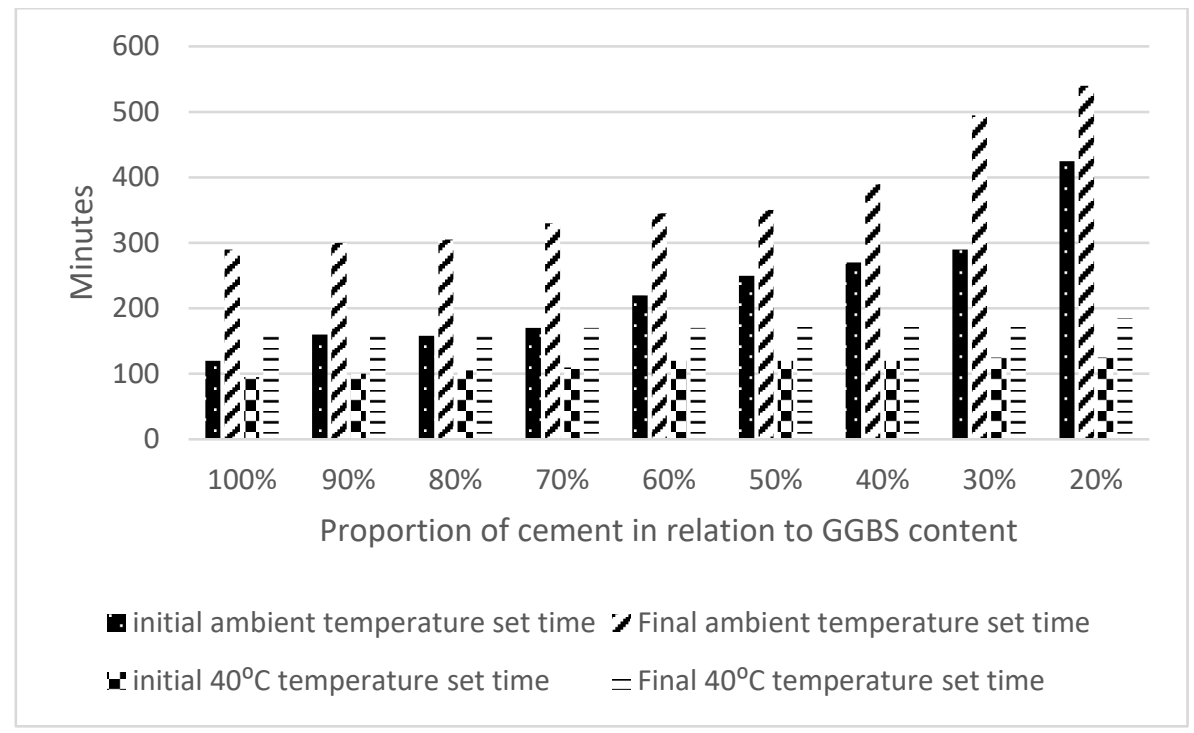

Figure 3. Initial and final setting times at ambient and $40^{\circ} \mathrm{C}$ air temperatures.

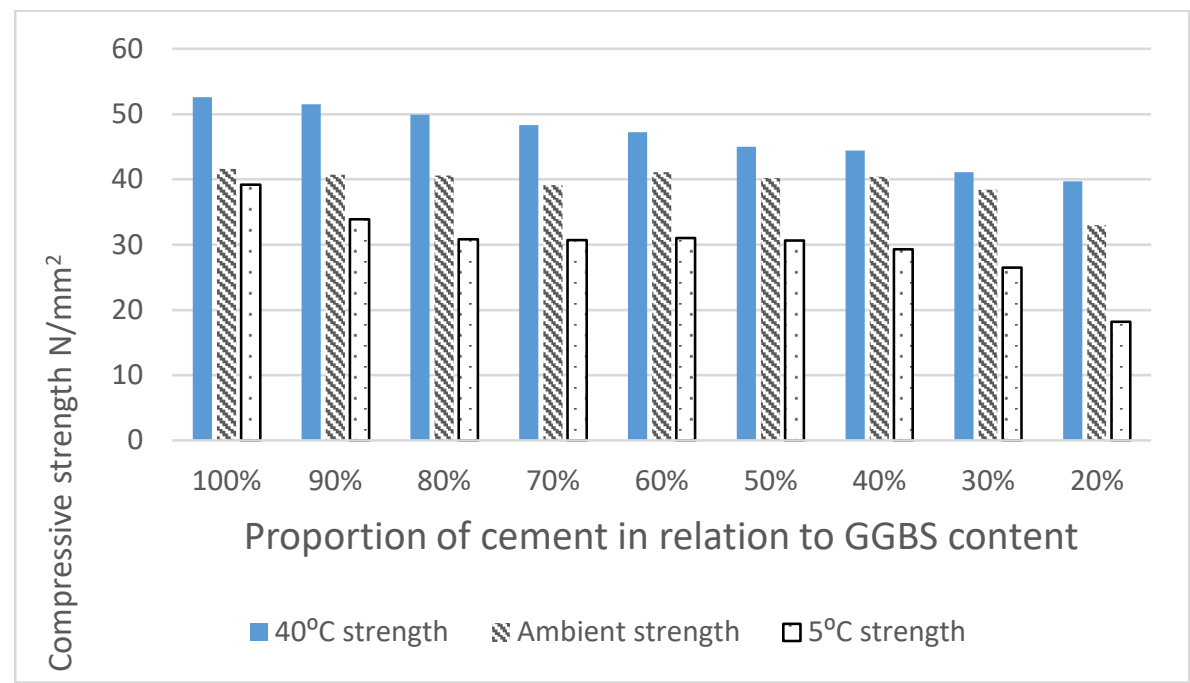

Figure 4. 28 day compressive strength $-40^{\circ} \mathrm{C}$, Ambient and $5^{\circ} \mathrm{C}$ cured specimen strength comparison

\section{Conclusion}

The cement replacement does not significantly affect the strength development of a ternary cement until 60/70\% of the cement has been replaced where the curing conditions are in the region of $20^{\circ} \mathrm{C}$.

Small cement replacements affect the strength development process of ternary cement mixes when the temperature is around $5^{\circ} \mathrm{C}$. Cement replacement with GGBS slows the initial and final setting of the mortar at all temperatures.

\section{References}

[1] Richardson AE, Coventry K. Early life freeze/thaw durability of Type 1 polypropylene fibre and ground granulated blast furnace slag concretes. In: Second International Conference on Sustainable Construction Materials and Technologies. Ancona, Italy: Università Politecnica delle Marche; 2010. p. 647 - 654.

[2] Richardson AE, Walker S, Hart A. Comparative thermal performance test for GGBS and OPC concrete mixes. In: Ecozoom, International Conference on Sustainability in Building. Denmark: VIA University College Denmark; 2009. p. $346-351$. 
[3] Kirton P, Richardson A, Agnew B. Thermo-mechanical performance of concrete with alternative binder material. Structural Survey. 2013;31(5):368-386.

[4] Bijen J. Benefits of slag and fly ash. Construction and building materials. 1996;10(5):309-314.

[5] Barnett SJ, Soutsos MN, Millard SG, Bungey JH. Strength development of mortars containing ground granulated blast-furnace slag: Effect of curing temperature and determination of apparent activation energies. Cement and Concrete Research. 2006;36(3):434-440.

[6] Escalante JI, Gomez LY, Johal KK, Mendoza G, Mancha H, Mendez J. Reactivity of blast-furnace slag in Portland cement blends hydrated under different conditions. Cement and Concrete Research. 2001;31 (10): 1403-1409.

[7] Roy DM, Idorn GM. Hydration, structure and properties of blast furnace slag cements, mortars and concrete. ACI Journal. 1982; 79(6):444-457.

[8] Tazawa EI, Miyazawa S. Influence of cement and admixture on autogenous shrinkage of cement paste. Cement and concrete research. 1995;25(2):281-287.

[9] Pinto RC, Hover KC. Application of maturity approach to setting times. Materials Journal. 1999;96(6):686691.

[10] Wade SA, Nixon JM, Schindler AK, Barnes RW. Effect of temperature on the setting behavior of concrete. Journal of Materials in Civil Engineering. 2010;22(3):214-222.

[11] Brooks JJ, Johari MM, Mazloom M. Effect of admixtures on the setting times of high-strength concrete. Cement and Concrete Composites. 2000;22(4):293-301.

[12] Eren O, Brooks JJ, Çelik T. Setting times of fly ash and slag-cement concretes as affected by curing temperature. Cement, Concrete and Aggregates. 1995; 17(1):11-17.

[13] Alshamsi AM. Stiffening rates of blended-cement pastes in hot climates. Advances in cement research. 2001;13(1):11-16.

[14] BS EN 196-3:2005 +A1:2008. (E) Methods of testing cement - Part 3: Determination of setting times and soundness ICS 91.100.10

[15] Richardson A, editor. Re-use of materials and by-products in construction, waste minimisation and re-cycling. Green Energy and Technology, Springer Publishing; 2013. ISSN 1865-3529 (Richardson chapters, 1 and 3)

(C) 2019 by the author(s). This work is licensed under a Creative Commons Attribution 4.0 International License (http://creativecommons.org/licenses/by/4.0/). Authors retain copyright of their work, with first publication rights granted to Tech Reviews Ltd. 